\title{
Physical, Bioactive and Textural Properties of Oleaster (Elaeagnus angustifolia L.) Fruit from Different Locations in Turkey
}

\author{
Meric Simsek $^{1, a, a^{*}, \text { Özge Süfer }}{ }^{1, b}$ \\ ${ }^{I}$ Department of Food Engineering, Osmaniye Korkut Ata University, 80000 Osmaniye, Turkey \\ *Corresponding author \\ A R T I C L E IN F O A B S T R A C T \\ Research Article \\ The objective of this study was to evaluate the physical, bioactive and textural properties of oleaster \\ fruits grown in different locations of Turkey. The oleaster fruits were obtained from Aksaray, Niğde \\ and İzmir cities and their crumb and crust parts were analyzed individually and freshly. In terms of \\ color, the crust and crumb of oleaster fruits from İzmir had the darkest color with $L^{*}$ values of \\ Received : 25/10/2020 \\ Accepted : 12/11/2020 \\ $46.81 \pm 4.06$ and $78.91 \pm 4.97$ among all tested fruits from different locations, respectively. Total of \\ phenolic (TP), flavonoid (TF) and tannin (TT) content (C) and as well antioxidant activities (AA) \\ of oleaster fruits were determined for the crust and crumb of oleaster fruits. The highest TPC \\ $(22.30 \pm 1.75 \mathrm{mg}$ gallic acid equivalent/g DM), TFC $(16.24 \pm 1.49 \mathrm{mg}$ catechin equivalent/g DM $)$ and \\ AA $(14.05 \pm 0.55 \mu \mathrm{mol}$ trolox equivalent/g DM) by DPPH were found in the crust of Aksaray oleaster \\ fruits. In addition, the crumb of Aksaray oleaster fruit had the highest TPC (16.44 $\pm 1.67 \mathrm{mg}$ gallic \\ Keywords: \\ Oleaster \\ Phenolics \\ Flavonoid \\ Tannin \\ Texture \\ acid equivalent/g DM) among the crumbs of oleaster fruits from different locations. Furthermore, \\ there was no significant difference among the texture of crust and crumb of oleaster fruits obtained \\ from different locations. Results showed the growing location of oleaster fruits had a significant \\ influence on the physical and bioactive properties of fruits. Also, this study indicated that oleaster \\ fruits were rich in bioactive compounds; therefore, they could be incorporated into foods to design \\ functional foods.
}

\section{Introduction}

Oleaster (Elaeagnus angustifolia L.) or Russian olive, which has reddish- or yellowish-brown elliptic fruit and hard skin, belongs to Elaeagnacea family. It is cultivated in Europe, Asia and North America (Öztürk et al., 2018). Total oleaster production of Turkey was reported as 4141 tons (TÜİK, 2019). Its significant amount is produced in the Central Anatolia region while the rest is provided from the Aegean region (Durmuş and Yiğit, 2003).

Oleaster contains carbohydrates, protein, vitamins and minerals (Y1ldırım et al., 2015). The dominant sugars were identified as fructose (27\%) and glucose $(22.3 \%)$ (Ayaz and Bertoft, 2001). Also, oleaster fruit is rich in phenolic acids, flavonoids and tannins (Abizov et al., 2008; Ayaz and Bertoft, 2001; Bucur et al., 2009; Zeng et al., 2009). Among phenolic acids, 4-hydroxybenzoic acid and caffeic acid were found to be the major phenolic compounds in oleaster fruit (Ayaz and Bertoft, 2001).

Since the oleaster has been consumed either fresh or dried as an appetizer, the use of oleaster fruit has not received enough attention in food industry. In fact, the sweet taste and dry texture of oleaster fruit enable to use in the form of flour in food. Therefore, some researchers incorporated the oleaster flour into various food such as ice cream (Çakmakçı et al., 2015), yoghurt (Öztürk et al., 2018), cookies (Sahan et al., 2019) and doughnut (Sarraf et al., 2017) as an alternative functional ingredient.

Due to its composition, oleaster has several health benefits such as antimicrobial, anti-inflammatory (Ahmadiani et al., 2000) and antioxidant (Faramarz et al., 2015; Wang et al., 2013). However, the physical, chemical and bioactive properties of the oleaster fruit may differ due to the soil, climate and ecological condition in which it is grown (Saboonchian et al., 2014).

The objective of this study was to investigate the physical, bioactive and textural properties of oleaster fruits obtained from different locations of Turkey. The information provided from this study could be useful for researchers and as well food industry regarding selecting the raw material from a specific location when a functional food would like to be designed with the oleaster fruit. 


\section{Materials and Methods}

\section{Materials}

The oleaster (Elaeagnus angustifolia L.) fruits were collected from the local gardens in İzmir, Aksaray and Niğde in Turkey. Folin \& Ciocalteu's phenol reagent, Folin-Denis' reagent, gallic acid, sodium bicarbonate, 2,2Diphenyl-1-picrylhydrazyl, trolox, catechin, sodium nitrate, aluminum chloride, 2,4,6-Tris (2-pyridyl)-striazine, iron chloride and methanol were bought from Merck (Darmstadt, Germany).

\section{Moisture Content Assay}

The moisture content of fresh oleaster fruits was determined according to AOAC method. The fresh oleaster fruit $\left(\mathrm{W}_{1}\right)$ were weighed into cups and hold at $80^{\circ} \mathrm{C}$ for 24 $\mathrm{h}$ in the oven. After reaching constant weight, the cups were measured $\left(\mathrm{W}_{2}\right)$ and the moisture content $(\%)$ was calculated using Eq. (1);

$$
\text { Moisture content }(\%)=\frac{\mathrm{W}_{1}-\mathrm{W}_{2}}{\mathrm{~W}_{1}} \times 100
$$

\section{Color Assay}

Color parameters ( $L^{*}$ (lightness), $a^{*}$ (rednessgreenness) and $b^{*}$ (yellowness-blueness)) of oleaster fruits were detected by a digital portable color meter (CR-400, Konica Minolta, Japan). Each measurement was repeated five times.

\section{Bioactive Compounds Extraction}

The extraction of bioactive compounds from oleaster fruit samples was performed according the method stated by Bennett et al. (2011). The oleaster fruit samples (1 g) were mixed with $80 \%$ methanol and then, the mixture was sonicated for $20 \mathrm{~min}$ at $25^{\circ} \mathrm{C}$ (Selecta Ultrasons HD, Barcelona). Afterwards, it was centrifuged at $3500 \mathrm{~g}$ for 15 min (Universal 320 R, Hettich, Tuttlingen, Germany) and filtered. The extracts were used as fresh for all analyses.

\section{Total Phenolic Content Assay}

Folin-Ciocalteu assay was used to determine total phenolic content (TPC) of oleaster fruit samples (Irakli et al., 2018). In this assay, Folin \& Ciocalteu reagent $(0.5 \mathrm{~mL})$ was added onto the extract $(0.5 \mathrm{~mL})$ and then, mixed with $\mathrm{Na}_{2} \mathrm{CO}_{3}$ solution $(3 \mathrm{~mL})$. The obtained mixture was incubated at dark for $30 \mathrm{~min}$. After the incubation, the absorbance values were read using the spectrophotometer (UV-1800, Schimadzu, Japan). TPC results were indicated as mg gallic acid equivalent/g dry matter of oleaster fruit (mg GAE/g DM). The assay was conducted in triplicate.

\section{Total Flavonoid Content Assay}

Total flavonoid content (TFC) of oleaster fruit samples was carried out using the procedure of M'hiri et al. (2015). The extract $(0.3 \mathrm{~mL})$ was mixed with $5 \% \mathrm{NaNO}_{3}(0.3 \mathrm{~mL})$ solution. Then, $10 \% \mathrm{AlCl}_{3}$ solution $(0.3 \mathrm{~mL})$ was added to the mixture. After the incubation for $10 \mathrm{~min}, 10 \% \mathrm{NaOH}$ solution $(4 \mathrm{~mL})$ was poured onto the mixture. The absorbance values were read at $510 \mathrm{~nm}$ using the spectrophotometer. The analysis was run in triplicate and TFC was given as mg catechin equivalent/g dry matter of oleaster fruit (mg CE/g DM).

\section{Total Tannin Content Assay}

Total tannin content (TTC) of oleaster fruit samples was carried out using the method given by Li et al. (2015). The extract $(0.2 \mathrm{~mL})$ was mixed with Folin-Dennis' reagent $(1.25 \mathrm{~mL})$, then $10 \% \mathrm{Na}_{2} \mathrm{CO}_{3}$ solution $(2.5 \mathrm{~mL})$ was added and the volume of the mixture was completed to $25 \mathrm{~mL}$ with distilled water. This mixture was held at dark for $30 \mathrm{~min}$ and the absorbance values were recorded at 700 $\mathrm{nm}$ using the spectrophotometer. Results were expressed as $\mathrm{mg}$ tannic acid equivalent/g dry matter of oleaster fruit (mg TAE/g DM). This analysis was performed in triplicate.

\section{Antioxidant Activity Assay (DPPH Method)}

Antioxidant activity (AA) assay of oleaster fruit samples was performed using the method of Aghraz et al. (2018). DPPH of $2 \mathrm{~mL}$ (in 100\% methanol) was mixed with the extract $(0.1 \mathrm{~mL})$ and the mixture was kept at dark for $30 \mathrm{~min}$. The absorbances were read at $517 \mathrm{~nm}$ using the spectrophotometer. The assay was carried out in triplicate. AA was calculated as $\mu$ mol trolox equivalent/g dry matter of oleaster fruit ( $\mu \mathrm{mol} \mathrm{TE} / \mathrm{g} \mathrm{DM})$.

\section{Antioxidant Activity Assay (FRAP Method)}

AA of oleaster fruit samples was also determined by FRAP method (Szydłowska-Czerniak et al., 2008). First of all, FRAP reagent consisted of $20 \mathrm{mM} \mathrm{FeCl}_{3}(2.5 \mathrm{~mL}), 10$ $\mathrm{mM}$ TPTZ solution $(2.5 \mathrm{~mL})$ and $0.1 \mathrm{M}$ acetate buffer $(25$ $\mathrm{mL})$ was prepared. Afterwards, FRAP reagent $(2 \mathrm{~mL})$ added onto the extract $(0.3 \mathrm{~mL})$ and then it was completed to total volume of $10 \mathrm{~mL}$ with distilled water. The absorbance values were obtained at $593 \mathrm{~nm}$ using a spectrophotometer. Results were expressed as $\mu \mathrm{mol} \mathrm{TE} / \mathrm{g}$ DM. The assay was run in triplicate.

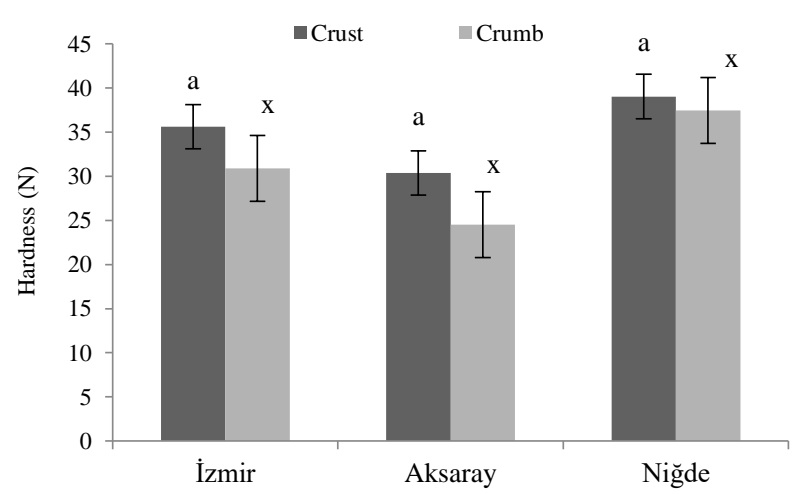

Figure 1. Hardness values of oleaster fruits from different locations of Turkey

(Statistical evaluation was not conducted between crust and crumb of same samples)

Table 1. The color values of crust and crumb of oleaster fruits

\begin{tabular}{l|ccc}
\hline Location & $L^{*}$ & $a^{*}$ & $b^{*}$ \\
\hline \multicolumn{4}{|c}{ Crust } \\
\hline İzmir & $46.81^{\mathrm{b}} \pm 4.06$ & $19.80^{\mathrm{a}} \pm 1.98$ & $24.27^{\mathrm{b}} \pm 3.31$ \\
Aksaray & $61.54^{\mathrm{a}} \pm 4.71$ & $13.16^{\mathrm{b}} \pm 3.68$ & $33.26^{\mathrm{a}} \pm 3.50$ \\
Niğde & $58.96^{\mathrm{a}} \pm 7.91$ & $15.83^{\mathrm{b}} \pm 4.62$ & $34.52^{\mathrm{a}} \pm 8.32$ \\
\hline \multicolumn{4}{|c}{ Crumb } \\
\hline İzmir & $78.91^{\mathrm{y}} \pm 4.97$ & $2.98^{\mathrm{x}} \pm 1.46$ & $17.92^{\mathrm{z}} \pm 2.81$ \\
Aksaray & $81.85^{\mathrm{x}} \pm 1.96$ & $1.48^{\mathrm{y}} \pm 0.78$ & $26.88^{\mathrm{x}} \pm 2.42$ \\
Niğde & $82.59^{\mathrm{x}} \pm 3.66$ & $1.51^{\mathrm{y}} \pm 0.73$ & $20.86^{\mathrm{y}} \pm 1.41$ \\
\hline Same superscript in a column indicates no significant differences \\
(P>0.05).
\end{tabular}


Table 2. Total phenolic, flavonoid, tannin contents and antioxidant activities of different oleaster fruits

\begin{tabular}{|c|c|c|c|c|c|}
\hline Region & $\begin{array}{c}\text { TPC } \\
\text { (mg GAE/g DM) }\end{array}$ & $\begin{array}{c}\text { TFC } \\
(\mathrm{mg} \mathrm{CE} / \mathrm{g} \mathrm{DM})\end{array}$ & $\begin{array}{c}\text { TTC } \\
(\mathrm{mg} \mathrm{TAE} / \mathrm{g} \mathrm{DM})\end{array}$ & $\begin{array}{c}\text { AA by DPPH } \\
(\mu \mathrm{mol} \text { TE/g DM })\end{array}$ & $\begin{array}{c}\text { AA by FRAP } \\
(\mu \mathrm{mol} \mathrm{TE} / \mathrm{g} \mathrm{DM})\end{array}$ \\
\hline \multicolumn{6}{|c|}{ Crust } \\
\hline İzmir & $15.91^{b} \pm 8.73$ & $5.99^{b} \pm 0.45$ & $61.88^{\mathrm{a}} \pm 2.38$ & $6.28^{c} \pm 1.50$ & $4.86^{\mathrm{a}} \pm 1.09$ \\
\hline Aksaray & $22.30^{\mathrm{a}} \pm 1.75$ & $16.24^{\mathrm{a}} \pm 1.49$ & $63.67^{\mathrm{a}} \pm 1.02$ & $14.05^{\mathrm{a}} \pm 0.55$ & $6.65^{\mathrm{a}} \pm 0.55$ \\
\hline Niğde & $13.43^{\mathrm{b}} \pm 1.20$ & $7.69^{b} \pm 1.30$ & $54.32^{a} \pm 5.72$ & $8.37^{\mathrm{b}} \pm 0.26$ & $4.44^{\mathrm{a}} \pm 0.35$ \\
\hline \multicolumn{6}{|c|}{ Crumb } \\
\hline İzmir & $12.42^{x y} \pm 1.94$ & $6.54^{x} \pm 2.68$ & $49.58^{x} \pm 3.18$ & $5.01^{z} \pm 0.17$ & $1.99^{\mathrm{y}} \pm 1.08$ \\
\hline Aksaray & $16.44^{x} \pm 1.67$ & $3.10^{\mathrm{x}} \pm 0.01$ & $23.85^{\mathrm{x}} \pm 0.01$ & $6.01^{y_{ \pm}} \pm 0.11$ & n.d. \\
\hline Niğde & $10.58^{\mathrm{y}} \pm 1.12$ & $5.64^{x} \pm 0.90$ & $58.28^{x} \pm 6.06$ & $11.56^{\mathrm{x}} \pm 0.32$ & $4.82^{x} \pm 0.03$ \\
\hline
\end{tabular}

Same superscript in a column indicates no significant differences (P>0.05). TPC: Total phenolic content, AA: Antioxidant activity, TFC: Total flavonoid content, TTC: Total tannin content, GAE: Gallic acid equivalent, CE: Catechin equivalent, TE: Trolox equivalent, TAE: Tannic acid equivalent, DM: Dry matter (it should be added after TAE: Tannic acid equivalent), n.d.=not determined

\section{Texture Profile Analysis}

Hardness of the crust and crumb of the oleaster fruits was measured by CT3 Texture Analyzer (Brookfield, Germany). Texture profile analysis was conducted, and conditions were specified as follows; the load cell of 4500 $\mathrm{g}, 0.067 \mathrm{~N}$ of trigger load, $1 \mathrm{~mm} / \mathrm{s}$ test speed and $60 \%$ of the distance were used in the compression mode.

\section{Statistical Analysis}

The physical, bioactive and textural properties of oleaster fruit samples were analyzed using an analysis of variance test (one-way ANOVA). Duncan test was applied to compare the means of each assay using SPSS 18 trial version (SPSS Inc., Chicago, IL).

\section{Results and Discussion}

\section{The Color Parameters}

The color values ( $L^{*}, a^{*}$ and $\left.b^{*}\right)$ of crust and crumb of oleaster fruits were shown in Table 1. $L^{*}, a^{*}$ and $b^{*}$ values of the crust of oleaster fruits from İzmir were significantly different $(\mathrm{P}<0.05)$ from those from those of Aksaray and Niğde. The same trend was also seen for the crumb of oleaster fruits from İzmir. The lowest $L^{*}(46.81 \pm 4.06)$ and $b^{*}(24.27 \pm 3.31)$ and highest $a^{*}(19.80 \pm 1.98)$ were measured for the crust of oleaster fruits from İzmir. In general, higher $L^{*}$ and lower $a^{*}$ values were determined for the crumb of oleaster fruits when compared to the ones of crust of oleaster fruits. The increase in $L^{*}$ values in the crumb could be related to direct sun exposure of crumb of oleaster fruits.

\section{The Bioactive Properties}

The bioactive properties (TPC, TFC, TTC, and AA) of crust and crumb of oleaster fruit extracts were given in Table 2. In this study, the crust and crumb of oleaster fruit were evaluated separately since there has been an interest to use the crumb part of oleaster fruits in the flour form in the literature. However, the crust of oleaster fruit could be valorized by mixing with the crumb or individually. The crust and crumb of extracts of the oleaster fruit from Aksaray had the highest TPC $(22.30 \pm 1.75 \mathrm{mg} \mathrm{GAE} / \mathrm{g} \mathrm{DM}$ and $16.44 \pm 1.67 \mathrm{mg} \mathrm{GAE} / \mathrm{g} \mathrm{DM}$, respectively). These results were similar to the findings of Çakmakçı et al. (2015) who reported TPC of the flour and crust lyophilized oleaster extract as 27.78 and $31.11 \mathrm{mg} \mathrm{GAE} / \mathrm{g}$, respectively. Hassanzadeh and Hassanpour (2018) found the mean value of TPC of peel and pulp of oleaster grown in Iran as 518.07 and $480.16 \mathrm{mg} \mathrm{GAE} / 100 \mathrm{~g}$ fresh weight, respectively. In another study, TPC of extract obtained from oleaster grown in Tunisia was reported as $84.04 \pm$ $0.01 \mathrm{mg} \mathrm{GAE} / \mathrm{g}$ DM (Hanene et al., 2015). Our findings and results of previous studies clearly demonstrated that the TPC of oleaster fruits may change with the cultivars, genotypes, climate conditions and geographical locations (Hassanzadeh and Hassanpour, 2018).

TFC of the extracts obtained from the crust and crumb of oleaster fruit varied between $5.99 \pm 0.45$ and $16.24 \pm$ $1.49 \mathrm{mg} \mathrm{CE} / \mathrm{g} \mathrm{DM}$, and $3.10 \pm 0.01$ and $6.54 \pm 2.68 \mathrm{mg}$ CE/g DM, respectively. TFC of crust of Aksaray oleaster fruit was significantly higher than those from İzmir and Niğde oleaster fruits; however, TFC of oleaster crumb from different locations were not significantly different. The highest TFC $(16.24 \pm 1.49 \mathrm{mg}$ CE/g DM $)$ was observed in the extracts obtained from Aksaray oleaster crust. Faramarz et al. (2015) reported TFC of peel and pulp of Iranian oleaster as $0.64-1.13 \mathrm{mg}$ and $0.62-1.90 \mathrm{mg} \mathrm{CE} / \mathrm{g}$ which was lower than our findings. TFC of flour and crust lyophilized oleaster extract was determined as 36.36 and $32.73 \mathrm{mg}$ quercetin equivalents/g, respectively (Çakmakçı et al., 2015). In the study of Hassanzadeh and Hassanpour (2018), TFC of peel and pulp of Iranian oleaster was reported as 121.55 and $148.52 \mathrm{mg} \mathrm{CE} / 100 \mathrm{~g}$ fresh weight, respectively. The variations in the TFC of oleaster in various studies could be explained with the differences in the genetic, climate or environmental conditions.

Interestingly, there was no significant change among the TTC of extracts obtained from the crust and as well crumb of oleaster fruits from different locations. The TTC changed between $54.32 \pm 5.72$ and $63.67 \pm 1.02 \mathrm{mg} \mathrm{TAE} / \mathrm{g}$ $\mathrm{DM}$, and $23.85 \pm 0.01$ and $58.28 \pm 6.06 \mathrm{mg} \mathrm{TAE} / \mathrm{g} \mathrm{DM}$ for the extract of the crust and crumb of oleaster fruits, respectively. These results were consistent with the findings of Hanene et al. (2015) who reported condensed tannin as $40.08 \pm 0.01 \mathrm{mg} \mathrm{CE} / \mathrm{g} \mathrm{DM}$ in the extract of Tunisian oleaster.

AA of extracts from oleaster fruit crust and crumb was determined using DPPH and FRAP method. There was a significant change among the AAs of crust and crumb of oleaster fruits. The AA values detected by DPPH method were in the range of $6.28 \pm 1.50$ and $14.05 \pm 0.55 \mu \mathrm{mol} \mathrm{TE} / \mathrm{g}$ $\mathrm{DM}$, and $5.01 \pm 0.17$ and $11.56 \pm 0.32 \mu \mathrm{mol} \mathrm{TE} / \mathrm{g} \mathrm{DM}$ for the extract of crust and crumb of oleaster fruits, respectively. The highest AA $(14.05 \pm 0.55 \mu \mathrm{mol}$ and $11.56 \pm 0.32 \mu \mathrm{mol}$ $\mathrm{TE} / \mathrm{g} \mathrm{DM}$ ) of the extract of crust and crumb was seen in Aksaray and Niğde oleaster fruits. This could be expected 
due to the high TPC of Aksaray oleaster. Çakmakçı et al. (2015) found the $\mathrm{IC}_{50}$ value by DPPH method as 34.65 and $34.72 \mu \mathrm{g} / \mathrm{mL}$ for the flour and crust lyophilized oleaster extract. Hassanzadeh and Hassanpour (2018) showed the mean AA measured by DPPH for the oleaster peel and pulp as 74.71 and $53.76 \%$, respectively. Another study reported about AA by DPPH method as 86.95 and $91.78 \%$, respectively (Faramarz et al., 2015). On the other hand, in the present study, the AA values based on FRAP assay were not significantly different for the extract of crust from oleaster fruits of different places. The AA values changed between $4.44 \pm 0.35$ and $6.65 \pm 0.55 \mu \mathrm{mol} \mathrm{TE} / \mathrm{g}$ DM for the extract of oleaster crust. Previous studies reported AA values measured by FRAP assay as the range of 86-164.67 mg/100 $\mathrm{g}$ fresh weight for the oleaster pulp and 0.246 and 0.548 $\mathrm{mM} / \mathrm{mg}$ for the oleaster peel and pulp, respectively (Faramarz et al., 2015; Hassanzadeh and Hassanpour, 2018).

\section{Texture Profile Analysis}

The hardness values of the crust and crumb of oleaster fruits were presented in Figure 1. The hardness values of crust of oleaster fruits from different locations varied between 30.36 and $39.01 \mathrm{~N}$. There was no significant difference among the crust or crumb of oleaster fruits from different locations $(\mathrm{P}>0.05)$. The hardness values for the crumb ranged from 24.50 and $37.43 \mathrm{~N}$. The hardness of the crumb of oleaster fruits was lower compared to that of crust.

\section{Conclusion}

This study clearly showed that the physical and bioactive properties of oleaster fruits can change significantly due to the geographical location. The genotype, climate and environmental conditions greatly influence the fruit composition. In this study, there were significant differences among total phenolic and flavonoid content, total tannin content and antioxidant activities of fruits from different locations. Also, this study demonstrated that the cultivated region of oleaster fruit did not affect the hardness of oleaster fruit. In addition, this study evaluated the crust and crumb of the oleaster fruit individually which would present the detailed information to researchers and food industry. As a result, the oleaster fruit has a potential to incorporate into foods due to its high bioactive content.

\section{References}

Abizov EA, Tolkachev ON, Mal'tsev SD, Abizova EV. 2008. Composition of biologically active substances isolated from the fruits of Russian olive (Elaeagnus angustifolia) introduced in the European part of Russia. Pharm. Chem. J. 42: 696-698. https://doi.org/10.1007/s11094-009-0203-5

Aghraz A, Gonçalves S, Rodríguez-Solana R, Dra LA, Di Stefano V, Dugo G, Cicero N, Larhsini M, Markouk M, Romano A. 2018. Antioxidant activity and enzymes inhibitory properties of several extracts from two Moroccan Asteraceae species. South African J. Bot. 118: 58-64. https://doi.org/10.1016/ j.sajb.2018.06.017

Ahmadiani A, Hosseiny J, Semnanian S, Javan M, Saeedi F, Kamalinejad M, Saremi S. 2000. Antinociceptive and antiinflammatory effects of Elaeagnus angustifolia fruit extract. J. Ethnopharmacol. 72: 287-292. https://doi.org/10.1016/ S0378-8741(00)00222-1
AOAC, 2000. The Association of Official Agricultural Chemists, Seventeenth ed. Official Method of Analysis, Washington, DC, USA.

Ayaz FA, Bertoft E. 2001. Sugar and phenolic acid composition of stored commercial oleaster fruits. J. Food Compos. Anal. 14: 505-511. https://doi.org/10.1006/jfca.2001.1004

Bennett LE, Jegasothy H, Konczak I, Frank D, Sudharmarajan S, Clingeleffer PR. 2011. Total polyphenolics and anti-oxidant properties of selected dried fruits and relationships to drying conditions. J. Funct. Foods 3: 115-124. https://doi.org/10. 1016/ j.jff.2011.03.005

Bucur L, Vlase L, Istudor V, Popescu A, Hațieganu I, Davila C. 2009. HPLC-MS analysis of the polyphenols in two soft extracts of Elaeagnus angustifolia L. Note 2. Soft extract of young branches analysis. Farmacia, 57(6): 736-742.

Çakmakçı S, Topdaş EF, Kalın P, Han H, Şekerci PP, Köse L, Gülçin İ. 2015. Antioxidant capacity and functionality of oleaster (Elaeagnus angustifolia L.) flour and crust in a new kind of fruity ice cream. Int. J. Food Sci. Technol. 50: 472481. https://doi.org/10.1111/ijfs.12637

Durmuş E, Yiğit A. 2003. The fruit producing regions of Turkey. Frrat Univ. J. Soc. Sci. 13: 23-54.

Faramarz S, Dehghan G, Jahanban-Esfahlan A. 2015. Antioxidants in different parts of oleaster as a function of cultivar. BioImpacts 5: 79-85. https://doi.org/10.15171/ bi.2015.09

Hanene G, Aouadhi C, Hamrouni S, Mnif W. 2015. Antibacterial, antifungal and antioxidant activities of Tunisian Olea europaea Ssp. oleaster fruit pulp and its essential fatty acids. Int. J. Pharm. Pharm. Sci. 7: 52-55.

Hassanzadeh Z, Hassanpour H. 2018. Evaluation of physicochemical characteristics and antioxidant properties of Elaeagnus angustifolia L. Sci. Hortic. (Amsterdam). 238: 8390. https://doi.org/10.1016/j.scienta.2018.04.041

Irakli M, Chatzopoulou P, Ekateriniadou L. 2018. Optimization of ultrasound-assisted extraction of phenolic compounds: Oleuropein, phenolic acids, phenolic alcohols and flavonoids from olive leaves and evaluation of its antioxidant activities. Ind. Crops Prod. 124: 382-388. https://doi.org/10.1016/j. indcrop.2018.07.070

Li X, Wasila H, Liu L, Yuan T, Gao Z, Zhao B, Ahmad I. 2015. Physicochemical characteristics, polyphenol compositions and antioxidant potential of pomegranate juices from 10 Chinese cultivars and the environmental factors analysis. Food Chem. 175: 575-584. https://doi.org/10.1016/ j.foodchem.2014.12.003

M'hiri N, Ioannou I, Mihoubi Boudhrioua N, Ghoul M. 2015. Effect of different operating conditions on the extraction of phenolic compounds in orange peel. Food Bioprod. Process. 96: 161-170. https://doi.org/10.1016/j.fbp.2015.07.010

Öztürk Hİ, Aydın S, Sözeri D, Demirci T, Sert D, Akın N. 2018. Fortification of set-type yoghurts with Elaeagnus angustifolia L. flours: Effects on physicochemical, textural, and microstructural characteristics. LWT - Food Sci. Technol. 90: 620-626. https://doi.org/10.1016/j.lwt.2018.01.012

Saboonchian F, Jamei R, Hosseini Sarghein S. 2014. Phenolic and flavonoid content of Elaeagnus angustifolia L. (leaf and flower). Avicenna J. phytomedicine 4: 231-8. https://doi.org/10.22038/ajp.2014.1975

Sahan Y, Aydin E, Dundar AI, Altiner DD, Celik G, Gocmen D. 2019. Effects of oleaster flour supplementation in total phenolic contents, antioxidant capacities and their bioaccessibilities of cookies. Food Sci. Biotechnol. 28: 14011408. https://doi.org/10.1007/s10068-019-00589-6

Sarraf M, Sani AM, Atash MMS. 2017. Physicochemical, organoleptic characteristics and image analysis of the doughnut enriched with oleaster flour. J. Food Process. Preserv. 41: e13021. https://doi.org/10.1111/jfpp.13021

Szydłowska-Czerniak A, Dianoczki C, Recseg K, Karlovits G, Szłyk E. 2008. Determination of antioxidant capacities of vegetable oils by ferric-ion spectrophotometric methods. Talanta 76: 899-905. https://doi.org/10.1016/j.talanta. 2008.04.055 
TÜİK, 2019. Bitkisel Üretim İstatistikleri, İğde. Web adresi: https://data.tuik.gov.tr/tr/main-category-sub-categories-subcomponents2/\# (Access date: 21. 10. 2020)

Wang Y, Guo T, Li JY, Zhou SZ, Zhao P, Fan MT. 2013. Four flavonoid glycosides from the pulps of Elaeagnus angustifolia and their antioxidant activities, in: Advanced Materials Research. Trans Tech Publications Ltd, pp. 16-20. https://doi.org/10.4028/www.scientific.net/AMR.756-759.16
Yıldırım I, Gökçe Z, Yılmaz Ö. 2015. The investigation of biochemical content of Elaeagnus angustifolia. J. Turkish Chem. Soc. Sect. A Chem. 2: 34-41.

Zeng FS, Wang WW, Zhan YG, Xin Y. 2009. Establishment of the callus and cell suspension culture of Elaeagnus angustifolia for the production of condensed tannins. African J. Biotechnol. 8: 5005-5010. 